\title{
Increase in high risk sexual behaviour among homosexual men, London 1996-8: cross sectional, questionnaire study
}

\author{
Julie P Dodds, Anthony Nardone, Danielle E Mercey, Anne M Johnson
}

Editorial by Grulich

Department of Sexually

Transmitted

Diseases, Royal Free

and University

College Medical

School, London

WC1E 6AU

Julie P Dodds

research fellow

Anthony Nardone

senior research fellow

Danielle E Mercey

senior lecturer

Anne M Johnson

professor, epidemiology

group

Correspondence to:

J P Dodds

JDodds@gum.ucl.

ac.uk

BMJ 2000;320:1510-1

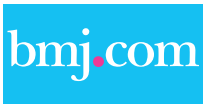

The members of the working group appear on the BMJ's website
The incidence of HIV infection among homosexual men in the United Kingdom is increasing despite efforts to reduce high risk sexual behaviour. ${ }^{1}$ The likelihood of engaging in high risk sexual behaviour may be increasing as new treatments reduce concern about infection. ${ }^{2}$ We report the results of a repeated survey of sexual behaviour among gay men in London.

\section{Methods and results}

A survey was conducted in 1996, 1997, and 1998 using the same methodology each year. ${ }^{3}$ A sampling frame was compiled of all commercial gay venues (bars, clubs, and saunas) and genitourinary medicine clinics within inner London. A sample of venue types and locations was then selected. Between 59 and 72 venues were sampled each year. Whenever possible the same venues were selected each year; if venues had closed they were replaced in the sample by similar ones. Health promotion workers distributed questionnaires with 16 items that covered demographic information and sexual behaviour. All men present at or queuing to enter a venue during a specific period were invited to participate. Altogether 6671 of 8384 (80\%) questionnaires distributed were returned; similar numbers were returned each year. Data were analysed using SPSS.

Respondents were aged from 15 to 78 years (median 31). Men sampled in 1998 were significantly older than in previous years (table). Altogether, 5660 of $6354(89 \%)$ of men were white and 4410 of $6232(71 \%)$ resided in inner London.

In each year, about a third of the men $(729 / 2263$ (32\%), 694/1943 (36\%), 730/1916 (38\%), respectively) reported having had unprotected anal intercourse during the previous year. However, in every year high risk sexual behaviour (for example, unprotected anal intercourse in the previous year) was significantly associated with younger age (occurring among 108/252 $(43 \%)$ of those aged under 25 and 103/340 (30\%) of those over 40, $\mathrm{P}<0.01$ in 1998) and recruitment from a genitourinary medicine clinic (odds ratio 1.39, 95\% confidence interval 1.13 to $1.71, \mathrm{P}<0.01$ in 1998).
Using 1996 as the baseline, there was a significant increase in the reporting of unprotected anal intercourse after adjusting for age and place of recruitment (1997 odds ratio 1.17 (1.03 to 1.33 ); 1998 odds ratio 1.23 (1.12 to 1.45$)$ ) (table). The adjusted odds of having had unprotected anal intercourse with partners whose HIV status was unknown or discordant also increased. However, there may be some misclassification error: of the 724 men who reported having had unprotected anal intercourse with partners of the same status, $118(16 \%)$ had never had an HIV test. There was no significant increase in the adjusted odds of having had an HIV test.

When only those 25 venues sampled every year were selected for analysis the increase in the adjusted odds of having had unprotected anal intercourse in the past year remained significant.

\section{Comment}

This is the first report of an increase in unsafe sex occurring among gay men in England; this increase has recently been observed in the United States. ${ }^{2}$

The $80 \%$ response rate showed that the survey was acceptable to participants. However, only those men who were socially active or using genitourinary medicine services were invited to participate. Although there are difficulties in interpreting trends in repeated cross sectional surveys, we believe that these results are important as they represent an apparent change in behaviour among gay men using the most frequented venues in London. ${ }^{34}$

HIV transmission can be reduced by ensuring that men have unprotected anal intercourse only with partners of a concordant HIV status; for this strategy to succeed, the importance of HIV testing must be promoted. Despite recent campaigns and the availability of new treatments, we found no evidence of an increase in the uptake of testing.

Our results, combined with the reported increase in gonorrhoea cases among gay men $^{5}$ and the increasing prevalence of HIV infection associated with longer

Changes in two measures of high risk sexual behaviour among gay men completing anonymous questionnaires in London. Odds ratios calculated using logistic regression and adjusted for age and place of recruitment

\begin{tabular}{|c|c|c|c|c|c|}
\hline & \multicolumn{3}{|c|}{ Year of questionnaire } & \multicolumn{2}{|c|}{ Significance } \\
\hline & 1996 & 1997 & 1998 & $\chi^{2}(\mathrm{df})$ & $\mathbf{P}$ \\
\hline$\%$ response & $75(2482 / 3318)$ & $80(2121 / 2639)$ & $85(2068 / 2427)$ & $94.7(1)$ & $<0.001^{*}$ \\
\hline Median (range) age (years) & $30(16-71)$ & $31(16-73)$ & $32(15-78)$ & 27.9 & $<0.001 \dagger$ \\
\hline $\begin{array}{l}\% \text { who had unprotected anal intercourse with }>1 \\
\text { partner in past year: }\end{array}$ & $32(729 / 2263)$ & $36(694 / 1943)$ & $38(730 / 1916)$ & $14.7(2)$ & $<0.001 \ddagger$ \\
\hline Adjusted odds ratio $(95 \% \mathrm{Cl})$ & 1 & 1.17 (1.03 to 1.33$)$ & $1.23(1.12$ to 1.45$)$ & & \\
\hline $\begin{array}{l}\text { \% who had sexual partner with unknown or } \\
\text { discordant HIV status in past year: }\end{array}$ & $18(375 / 2147)$ & $19(348 / 1851)$ & $21(378 / 1796)$ & $8.43(2)$ & $<0.02 \ddagger$ \\
\hline Adjusted odds ratio $(95 \% \mathrm{Cl})$ & 1 & $1.10(0.94$ to 1.3$)$ & $1.26(1.08$ to 1.49$)$ & & \\
\hline$\%$ who had an HIV test in past year: & $29(683 / 2347)$ & $31(614 / 2006)$ & $33(654 / 1994)$ & $3.5(2)$ & $0.17 \ddagger$ \\
\hline Adjusted odds ratio $(95 \% \mathrm{Cl})$ & 1 & $1.03(0.9$ to 1.19$)$ & $1.14(0.99$ to 1.31$)$ & & \\
\hline
\end{tabular}

*Using $\chi^{2}$ test for trend ( $1 \mathrm{df}$ )

†Using Kruskal-Wallis test.

fUsing $\chi^{2}$ test for variation in adjusted odds between years from logistic regression (2 df). 
survival, highlight the potential for the continuing spread of the epidemic and the need for more health promotion initiatives that have been shown to be effective.

We thank the Camden and Islington Health Authority for its financial support. We thank Dr Andrew Copas for statistical advice. We also thank members of the working group.

Contributors: AN, DEM, and AMJ initiated and designed the study. JPD and AN managed the project. JPD analysed the data, wrote the first draft, and coordinated subsequent revisions of the paper. All authors contributed to the final version of this paper. JPD and DEM are the guarantors.

Funding: Camden and Islington Health Authority.
Competing interests: None declared.

1 Communicable Disease Surveillance Centre. AIDS and HIV infection in the UK: monthly report. Commun Dis Rep CDR Wkly 1999;9:121-2.

2 From the Centers for Disease Control and Prevention. Increases in unsafe sex and rectal gonorrhea among men who have sex with men-San Francisco, California, 1994-1997. JAMA 1999:281:696-7.

3 Nardone A, Mercey DE, Johnson AM. Surveillance of high risk behaviour amongst homosexual men in a central London health authority Genitourin Med 1997;73:198-202

4 Nardone A, Dodds JP, Mercey DE, Johnson AM. Active surveillance of sexual behaviour among homosexual men in London. Commun Dis Public Health 1998; 1:197-201.

5 Sexually transmitted disease quarterly report: gonorrhoea in England and Wales. Commun Dis Rep CDR Wkly 1998;8:194-6.

(Accepted 22 February 2000)

\title{
Retrospective case note review of acute and inpatient stroke outcomes
}

\author{
Nabil Aly, Kevin McDonald, Michael Leathley, Anil Sharma, Caroline Watkins
}

The annual incidence of stroke in the community is about 2 per 1000 population, ${ }^{1}$ whereas among hospital inpatients it is 11 per $1000 .{ }^{2}$ However, a study that systematically and simultaneously identifies all inpatients experiencing stroke and all patients admitted with stroke does not exist. Previous work on stroke among inpatients has excluded some patients-for example, those with ${ }^{3}$ or without ${ }^{2}$ obvious iatrogenic predisposing factors. Similarly, although risk factors for stroke have been used as predictors of an event in the context of a study, ${ }^{3}$ these are often not documented clinically. Secondary prevention is dependent on identification and documentation of risk factors.

We compared outcomes and the identification and documentation of known risk factors in a cohort of patients admitted with a stroke or having had a stroke while in hospital (having been admitted to hospital with a primary diagnosis other than stroke).

\section{Subjects, methods, and results}

University Hospital Aintree serves a predominantly urban population of 250000 and admits about 32000 patients annually. Its stroke unit has 18 acute and 25 rehabilitation beds. Guidelines for the management of acute stroke are available throughout the hospital.
We identified all patients with a primary diagnosis of stroke (excluding transient ischaemic attacks and subarachnoid haemorrhages) on a stroke register. From October 1994 to March 1997, 100 inpatients with stroke and 1274 patients admitted with stroke were identified prospectively by a 24 hour, on-call stroke research team or retrospectively from the hospital discharge coding. Data collection was by retrospective review of case notes.

Median ages were 75 (interquartile range 67-82) years for inpatients and 74 (66-81) years for admitted patients. Fifty four (54\%) inpatients and $647(51 \%)$ admitted patients were female. Forty seven (47\%) inpatients and $537(42 \%)$ admitted patients were managed in the stroke unit.

The table shows the numbers of patients for whom known risk factors for stroke were clearly documented and the numbers for whom no documentation existed. According to documentation, cardiovascular risk factors were significantly higher in inpatients whereas previous strokes or transient ischaemic attacks were more common among admitted patients. Documentation was less complete for inpatients than for admitted patients.

Of the $80(80 \%)$ inpatients and $1092(86 \%)$ admitted patients who had computed tomography, $5(6 \%)$
Aintree Stroke Unit, Department of Medicine for the Elderly, University Hospital Aintree, Liverpool L9 7AL Nabil Aly specialist registrar Kevin McDonald research associate Michael Leathley research fellow

Anil Sharma consultant physician Caroline Watkins honorary research fellow

Correspondence to: A Sharma aksharma@ aintreestar. u-net.com

BMJ 2000;320:1511-2

Identification and documentation of known stroke risk factors among patients who had a stroke while in hospital and among patients who were admitted with stroke. Values are numbers (percentages) of patients

\begin{tabular}{|c|c|c|c|c|c|c|}
\hline & \multicolumn{3}{|c|}{ Identified } & \multicolumn{3}{|c|}{ Not documented } \\
\hline & Inpatients $(n=100)$ & Admitted patients ( $n=1274$ ) & $P$ value & Inpatients ( $n=100)$ & Admitted patients ( $n=1274$ ) & $P$ value \\
\hline Cardiac failure & $35(35)$ & $41(3)$ & $<0.01$ & $60(60)$ & $954(75)$ & $<0.01$ \\
\hline Atrial fibrillation & $32(32)$ & $253(20)$ & $<0.01$ & $38(38)$ & $223(18)$ & $<0.01$ \\
\hline Myocardial infarction & $25(25)$ & $181(14)$ & $<0.01$ & $30(30)$ & $207(16)$ & $<0.01$ \\
\hline Angina & $19(19)$ & $138(11)$ & $<0.03$ & $68(68)$ & $830(65)$ & $>0.61$ \\
\hline Hypertension & $31(31)$ & $480(38)$ & $>0.19$ & $30(30)$ & $196(15)$ & $<0.01$ \\
\hline Diabetes mellitus & $11(11)$ & $149(12)$ & $>0.88$ & $33(33)$ & $195(15)$ & $<0.01$ \\
\hline Previous stroke & $16(16)$ & $329(26)$ & $<0.04$ & $38(38)$ & $188(15)$ & $<0.01$ \\
\hline Previous transient ischaemic attack & $9(9)$ & $240(19)$ & $<0.02$ & $56(56)$ & $334(26)$ & $<0.01$ \\
\hline Ever smoked & 39 (39) & 685 (54) & $<0.01$ & $20(20)$ & $162(13)$ & $>0.05$ \\
\hline
\end{tabular}

All tests were with Yates's corrected $\chi^{2}$. 